\title{
Healthcare Services Expenditure: A Case Study in Isfahan Province, Iran
}

\author{
Masuod Ferdosi ${ }^{1}$; Nematollah Akbari ${ }^{2}$; Ali Nemati $^{3{ }^{3}}$; ${ }^{\text {Maryam Mofid }}{ }^{4}$; Farzaneh Mohammadi ${ }^{5}$; \\ Ali Beigi Nasiri ${ }^{6}$
}

${ }^{1}$ Health Management and Economic Research Center, Isfahan University of Medical Sciences, Isfahan, IR Iran

${ }_{3}^{2}$ Department of Economic, University of Isfahan, Isfahan, IR Iran

3 Depart

${ }^{4}$ Department of Health Management and Economic, Isfahan University of Medical Sciences, Isfahan, IR Iran

${ }_{6}^{5}$ Department of Health Management and Economic, Tarbiat Modares University, Tehran, IR Iran

6 Jawaharlal Nehru Technological University, Hyderabad, India

${ }^{*}$ Corresponding author: Ali Nemati, Department of Health Management and Economic, Tehran University of Medical Sciences, Tehran, IR Iran. Tel: +98-9389059580,

E-mail:ali_nemati96@yahoo.com

Received: September 7, 2014; Revised: December 23, 2014; Accepted:January 6, 2015

\begin{abstract}
Background: Determining and understanding of healthcare costs and its financing method is one of the most important subjects understatement of which can cause such major problems as excessive health costs for households due to the high rate of out-of-pocket expenses.

Objectives: The current study aimed to analyze the healthcare costs and determine the share of Isfahan province, Iran, from the total healthcare costs of the country from 2006 to 2011.

Materials and Methods: It wasa retrospective and descriptive-analytical study. The required statistical data were gathered from statistical yearbooks of the country and the province, the website of the World Bank, the statistics provided by the Healthcare Department of Isfahan and Kashan Universities of Medical Sciences and the statistical data provided by Iran Statistics Center in 2011, all covering the period of six years from 2006 to 2011. Excel software was used for data analysis and computations of the research.

Results: During this period, the annual growth average of healthcare and treatment costs were $12 \%$ and $20 \%$, respectively. The share of the healthcare sector declined from $33 \%$ in 2006 to $25.4 \%$ in 2011. In other words, healthcare cost per capita, being about one second of the treatment cost per capita, reduced to a third of treatment per capita in 2011.

Conclusions: Efficient allocation of financial resources in the healthcare system based on specific goals and strategies, coordination of public and private sectors in providing healthcare services, the rising share of the healthcare sector in GDP of the province and the country, and the preference of prevention over treatment measures can affect achieving the healthcare system goals and surmount challenges such as pay-out-of-pocket and rising healthcare costs, particularly the costs of integrated treatment with full performance.
\end{abstract}

Keywords: Cost; Healthcare; Isfahan Province

\section{Background}

High amounts of direct payments on the part of the households are known as a malfunction in the healthcare system due to which the households are not only suffering from the diseases but also the direct financial burden (1). Funding of healthcare costs in low-income countries, especially in Asian countries is often done through payout-of-pocket and in the absence of pre-payment mechanisms such as the right to have healthcare insurance. When healthcare costs exceed the amount of household income or while the big part of the household costs are spent on healthcare compared to the cost of living and services other than medical, or a large share of household income is devoted to healthcare, it will impose heavy, namely crippling costs when facing an illness (2). In this case, particularly vulnerable households will face troubles due to financial intermediaries in accessing the medical services and providing the costs; they have to cut down on their other necessary expenses, which degrade the welfare of households. In addition, some households due to lack of financial sources are deprived of the process of treatment or follow-up steps, which degrades the healthcare of families and society. Therefore, considering the volume of healthcare payments and their share out of the household income are important factors that should be taken into account in the healthcare system policy making and planning (3).

In a study in eight countries to determine the fairness of healthcare costs, it was determined that pre-paid expenses among the various income deciles reflect less fluctuation and all income deciles spent the same proportion of their income on pre-paid healthcare costs. However, the situation was different in the case of pay-out-of-pocket costs. The rich people in India and Tanzania spent a greater proportion of their income on these kinds of expenses. In contrast, in Mexico, Pakistan and Brazil, the poor people spent a greater proportion of their income out-of-

Copyright (C) 2015, Ahvaz Jundishapur University of Medical Sciences. This is an open-access article distributed under the terms of the Creative Commons Attribution-NonCommercial 4.0 International License (http://creativecommons.org/licenses/by-nc/4.0/) which permits copy and redistribute the material just in noncommercial usages, provided the original work is properly cited. 
Ferdosi $\mathrm{M}$ et al.

pocket. The most unjust situation was observed in Vietnam in which pre-paid expenses in all deciles except the highest decile (the rich people) was about zero and the poor people spent a greater proportion of their income out-of-pocket directly (about 23\% of the total revenue) (4). According to World Bank figures, despite fluctuations, payment-out-of-pocket increased from 50.3\% in 2006 to $58.46 \%$ in 2011 . The highest amount of paying out of pocket was $59.38 \%$ in 2009 and the lowest one was equal to $59.38 \%$ in 2006 . According to the recent statistics, the share of treatment costs in Iran was so high that it led to the heavy pressure of healthcare costs on the people and an excessive rise of the public share in healthcare costs (5). According to the National Healthcare Services, more than $60 \%$ of the healthcare costs are funded by the direct payments of households while receiving services (6). In some studies, the payment rate of excessive healthcare costs was reported between $11.8 \%$ to $22.2 \%$ (7-9).

In a study by knaul et al. conducted in 12 countries of Latin America and the District of Caribe (LAC), the rate of excessive cost was determined about 30\%. The crippling cost was reported in the range of $1 \%$ to $25 \%$ among the countries (1). Xu et al. studied multiple effects of the variables under study on catastrophic household costs. While financial contribution of the households to the healthcare system (household healthcare costs) is more than $40 \%$ of the household costs (after exclusion of basic needs), families are trapped in crippling or catastrophic costs. They found that the share of crippling payments by paying out of pocket had various ranges among the countries (from 0 in Czech Republic and Slovak to over 10\% in Brazil and Vietnam). The highest rates of crippling payments were reported in some transition countries and South America (10). In a study carried out in Georgia, the results showed that $2.8 \%$ of household payments in 2000 i.e. more than $40 \%$ of the paying ability reached $11.7 \%$ in 2007 (11). In a study of healthcare costs of households in Nepal, Hotchkiss et al. estimated the ratio of healthcare costs to total family income in the first quartile (the lowest), second, third and fourth, 3.2\%, 4.6\%, 6.7\%, 7.8\%, respectively (12). In a similar study, do Rosario Giraldes estimated the share of medication costs from household income as one of the highest Gini indices (extreme inequality) while studying socio-economic equity indicators related to healthcare in the European Union countries (13). This issue was considered in Iran in recent years. In article 90 of the law of provision of the fourth plan, it is mentioned that equal accessibility to public healthcare services and reducing the proportion of low-income and vulnerable households in the payment of costs, resource distribution should be arranged in a way that the public fair financial participation index (90\%) be promoted and what people pay directly from their pockets should not exceed $30 \%$. Due to the high rate of paying out of pocket and inflation rate in Iran, it seems essential to study the healthcare cost, policy-making and appropriate decisionmaking in the healthcare sector.

\section{Objectives}

The current study aimed to analyze the healthcare costs and determine the share of Isfahan province, Iran, from the total healthcare costs of the country from 2006 to 2011.

\section{Materials and Methods}

This retrospective study was carried out with a descriptive-analytical design in 2011 in which the period of 6 years from 2006 to 2011 were analyzed. The study population was the Isfahan province and the statistical data were gathered from statistical yearbooks of the country, the website of the World Bank, the Statistics provided by the Healthcare Departments of Isfahan and Kashan Universities of Medical Sciences and statistical data provided by Iran Statistics Center in 2011. The data were analyzed regarding the healthcare and social healthcare insurance costs in urban and rural households in Isfahan province and compared with that of the country's average. Excel software was used for data analysis.

\section{Results}

\subsection{The Annual Average Net Costs of Healthcare for Household in Isfahan Province}

Annual healthcare costs of urban households had positive growth except in 2009. The costs were about 352.9 dollars in 2006 and 696.8 dollars in 2011. The annual healthcare costs of urban households diminished in 2009. The annual social healthcare insurance of urban households had an upward trend except in 2009 it reached from 157.5 dollars in 2006 to 339.4 dollars in 2011. With positive growth rates of about $29.65 \%, 7.4 \%$ and $13.8 \%$, these costs were about 157, 167, 191 dollars, respectively in the years 2006 to 2008 . The costs with a slight decrease were reported 183 dollars in 2009. The total annual healthcare costs of urban households follow the same trend as social healthcare insurance. Municipal Healthcare Services costs for the years 2006 and 2007 are equal to 510 and 692 dollars respectively. This rate reached 945 dollars with a negative growth of $7.8 \%$ in 2009 in comparison with the previous year. These costs increased to 1036 dollars in 2011 (Table 1).

The total annual healthcare costs of rural households had a positive growth trend in the years under study. As it was observed, the total annual healthcare costs of the rural households was 491 dollars in 2006 that reached 592 with a positive growth of $20.36 \%$ in 2007 and the following years. These amounts were 713 and 716 dollars (7.9 and 11.5 million rials) in 2010 and 2011, respectively. Variations in annual healthcare costs of rural households were largely similar to those of the rural households, the only difference was that these costs dropped to 565 dollars change in 2010. The upward trend of the mentioned costs was fixed as total annual healthcare costs of rural households from 2006 to 2009 . The annual social healthcare insurance of rural households of Isfahan province 
maintained its upward trend except for 2007 that decreased with slight change (10.8\%) and it was reported 214 dollars in 2011. The above costs were 136, 121, 144, 146 and 148 dollars with the growth rates of $26.6 \%,-10.8 \%, 19.32 \%$, $1.3 \%$ and $1.1 \%$, respectively from 2006 to 2011 . The annual healthcare and social healthcare insurance costs of rural households of the country increased from 2006 to 2009. The healthcare costs from 579 dollars in 2006 reached 725 dollars in 2011. The healthcare costs were 431 and 725 dollars, respectively, the figures 148 and 218 dollars were reported in the case of social healthcare insurance in 2006 and 2011, respectively.

\subsection{The Per Capita Cost of Healthcare in the Prov- ince}

According to the available statistics regarding the performance of the current budget, specific and acquisition of assets of Medical Sciences University of, Isfahan and Kashan, and considering the population statistics of Isfahan province during the years 2006 to 2011, the total per capita cost of funds and total per capita healthcare cost can be calculated. The following per capita healthcare and treatment costs are separately presented from specific and the current budget (Figure 1). The lowest per capita healthcare was about 13.5 dollars in 2006, and the highest one was 20.1 dollars in 2010 (124235 rials in 2006, and the highest one was 221145 rials in 2010, in which a $12 \%$ average annual growth was observed). The highest and lowest per capita treatment costs were in the years 2006 and 2011 with the amounts of 27.5 and 40.5 dollars, respectively, which show that the average annual growth is over $8.3 \%$.

The above diagram indicates that per capita healthcare cost increased from 2006 to 2011 but it declined slightly in 2011. However, per capita treatment cost increased in all these years. Also, the total contribution of healthcare sector dropped from $33 \%$ in 2006 to $25.4 \%$ in 2011 . In other words, per capita healthcare that was about one second of per capita treatment in 2006, reduced to one third of per capita treatment in 2011. According to the World Bank statistics, the per capita healthcare costs were rising from 2006 to 2010. Per capita healthcare costs were about 173.5 dollars in 2006. This amount was equal to 214, 279, 280 and 300 dollars respectively for the years 2007 to 2010 . The highest rate of growth in the healthcare costs per capita was observed in 2008.

Table 1. The Annual Average Net Costs of Household Healthcare in Isfahan Province ${ }^{\text {a }}$

\begin{tabular}{|c|c|c|c|c|c|c|}
\hline \multirow[t]{2}{*}{ Location } & \multicolumn{6}{|c|}{ The Average Cost of Healthcare, dollars } \\
\hline & 2006 & 2007 & 2008 & 2009 & 2010 & 2011 \\
\hline \multicolumn{7}{|l|}{ In Isfahan Province } \\
\hline \multicolumn{7}{|l|}{ Urban households } \\
\hline $\begin{array}{l}\text { The total cost of } \\
\text { healthcare }\end{array}$ & 510.48 & 692.21 & 1026.64 & 945.63 & 1014.47 & 1036.39 \\
\hline Healthcare costs & 352.95 & 523.57 & 834.67 & 762.94 & 775.34 & 696.89 \\
\hline $\begin{array}{l}\text { Social healthcare } \\
\text { insurance costs }\end{array}$ & 157.53 & 168.64 & 191.96 & 182.69 & 239.14 & 339.50 \\
\hline \multicolumn{7}{|l|}{ Rural households } \\
\hline $\begin{array}{l}\text { The total cost of } \\
\text { healthcare }\end{array}$ & 491.92 & 592.11 & 616.08 & 775.69 & 713.95 & 716.35 \\
\hline healthcare costs & 355.76 & 470.67 & 471.12 & 628.78 & 565.41 & 501.54 \\
\hline $\begin{array}{l}\text { Social healthcare } \\
\text { insurance costs }\end{array}$ & 136.17 & 121.44 & 144.96 & 146.92 & 148.54 & 214.81 \\
\hline \multicolumn{7}{|l|}{ In Iran } \\
\hline \multicolumn{7}{|l|}{ Urban households } \\
\hline Healthcare & 579.72 & 726.21 & 813.25 & 854.89 & 954.40 & 725.38 \\
\hline Healthcare costs & 431.27 & 555.39 & 614.22 & 637.31 & 716.89 & 506.86 \\
\hline $\begin{array}{l}\text { Social healthcare } \\
\text { insurance costs }\end{array}$ & 148.45 & 170.82 & 199.03 & 217.59 & 237.51 & 218.52 \\
\hline \multicolumn{7}{|l|}{ Rural households } \\
\hline Healthcare & 388.67 & 411.73 & 479.31 & 544.15 & 586.52 & 424.84 \\
\hline Healthcare costs & 299.52 & 324.47 & 376.47 & 430.77 & 474.07 & 331.04 \\
\hline $\begin{array}{l}\text { Social healthcare } \\
\text { insurance costs }\end{array}$ & 89.14 & 87.26 & 102.84 & 113.35 & 112.45 & 93.80 \\
\hline
\end{tabular}


Ferdosi M et al.

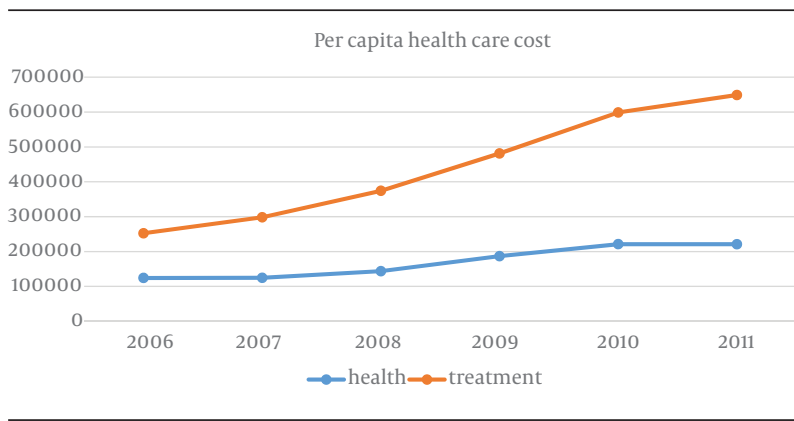

Figure 1. Per Capita Healthcare Cost From Part of Current Budget

\section{Discussion}

According to the obtained results, healthcare costs of Isfahan province were higher than the national average; therefore, healthcare and social healthcare insurance costs in the cities and villages of this province are higher than the national average of healthcare and social healthcare insurance costs. Meskari et al. showed that the average cost of healthcare insurance and the national average cost of healthcare of households in the cities with a growth rate of $16.7 \%$ reached from 4125 rial to 159716 rials (15.2 dollars to 17 dollars) and with a growth rate of $30.06 \%$ it reached from 25654 to 5192881 from 1981 to 2007 , and The average costs of medical insurance and healthcare were $23.3 \%$ and $34.5 \%$ in the rural areas, respectively. The current study showed that the increase of the healthcare costs could be a consequence of the emerging and chronic diseases, advances of diagnostic and therapeutic technology, and the aging of population (14). The study by Khosravi et al. showed that direct payments of villagers did not decrease even in the years following the implementation of rural insurance law (15). Annual social healthcare insurance costs of urban households increased from 162 dollars in 2006 to 337 dollars in the year 2011. Moreover, the social healthcare insurance costs of the country are reported as 151.8 dollars and 219 dollars for the years 2006 and 2011. The annual social healthcare costs of rural households in Isfahan province maintained its upward trend except for 2007, which had a slight downward change of $10.8 \%$, this amount reached from 136 dollars in 2006 to 214 dollars in 2011 . Social healthcare insurance costs of the country were 89 dollars in 2006 , and after a negative change in 2007 the highest rate of these costs was about 93dollarss in 2011. Based on the National Healthcare Services studies, the lower portion of the prepaid finance of the healthcare system is the most important reason for ineffectiveness of healthcare insurance payments as a reduction in direct payments of households (16). The current study indicated that despite the rising costs of social healthcare insurance the healthcare costs of households are high.

The costs rate of urban households in Isfahan province is higher than country's average. The total annual healthcare costs of urban households were 509 and 695 dollars, respectively in 2006 and 2007. The costs increased to 1038 dallars in 2011. The total annual healthcare costs of the rural households was 491 dollars in 2006 that reached 592 with a positive growth of $20.36 \%$ in 2007 and the following years. These amounts were 713 and 716 dollars (7.9 and 11.5 million rials) in 2010 and 2011, respectively.

The study by Kazemian et al. indicated that the Iranian urban household's healthcare cost is $68 \%$ more than that of the rural households (17). These findings are consistent with the previous Iranian study which estimated the exposure of households with catastrophic healthcare expenditures as $4 \%$ (18). Another Iranian study estimated this figure as $3.29 \%$ and $1.87 \%$ for the rural and urban areas of the country, respectively (19). On the other hand, other Iranian studies at regional level estimated this figure as $22.2 \%$ in Kermanshah province (20) and $11.7 \%$ in district 17 of Tehran, Iran (8). Of course, these great divergences could be because of the respective survey methods or data analysis, the possibility of high expenditures due to low access to healthcare services and also better access to these facilities in the capital compared to the other areas. According to a study in Georgia, $14.8 \%$ of households in the capital of the country faced with catastrophic expenditures, while it was $11.2 \%$ in east of the country and $10 \%, 1 \%$ in the western part of the country (11).

The results of the current study showed that healthcare costs are rising across the province and country, meanwhile much of the payments will be paid directly out of pocket. Increasing the share of healthcare costs on the part of households could reduce access of households to healthcare and cause the increase of the crippling costs. In fact, since households spend a high proportion of their disposable income on crippling healthcare costs, they will suffer great financial losses and may also be drawn into poverty. The share of healthcare sector in GDP is relatively low in Isfahan province and the country.

On the other hand, the study results indicated that the share of treatment costs were higher than healthcare costs in Isfahan province in all the years under study, it is supposed to represent the views and approaches to healthcare were instead of a preventive care prospect and it could be said the primary healthcare network faces issues. In addition, treatment-based diagnostic medication measures may not be based on evidence, which itself imposes certain costs.

Therefore, the allocation and distribution of financial resources in the healthcare system is one of the most basic elements of this system that on one hand is affected by plans and strategies of the system and on the other hand it is direct for performance and behavior. In this respect, considering the first level of healthcare services such as primary care and prevention should be a priority and the allocation rate of financial resources to the second and third levels should be planned and scheduled.

Therefore, due to the growing demand for healthcare, especially medical care, and considering the financial constraints, the health sector financing methods should 
be defined, and allocation of financial resources to different levels based on certain objectives and strategies and all sectors whether public or private should obey a regular and systematic framework in order to coordinate the healthcare servicing system both in provincial and national scales to achieve the healthcare system goals and overcome the challenges such as high level of paying out of pocket and rising healthcare costs especially integration treatment costs efficiently.

\section{Acknowledgements}

Authors thank the Healthcare Deputy of Isfahan University of Medical Sciences.

\section{Funding/Support}

The study was supported by Isfahan University of Medical Sciences.

\section{References}

1. Knaul FM, Arreola-Ornelas H, Mendez-Carniado O, Bryson-Cahn C, Barofsky J, Maguire R, et al. Evidence is good for your health system: policy reform to remedy catastrophic and impoverishing health spending in Mexico. Lancet. 2006;368(9549):1828-41.

2. Ghosh S. Catastrophic Payments and Impoverishment Due to Out-of-Pocket Health Spending: The Effects of Recent Health Sector Reforms in India. Electronic J. 2010.

3. Ghiasvand H, Sha'baninejad H, Arab M, Rashidian A. Hospitalization and catastrophic medical payment: evidence from hospitals located in Tehran. Arch Iran Med. 2014;17(7):507-13.

4. World Health Organization.. Health systems improving performance.Geneva:WHO; 2000.

5. World Bank.. World Bank. 2013. Available from: http:/www.worldbank.org.
6. Hajizadeh M, Nghiem HS. Out-of-pocket expenditures for hospital care in Iran: who is at risk of incurring catastrophic payments? Int J Health Care Finance Econ. 2011;11(4):267-85.

7. Kavosi Z, Rashidian A, Pourmalek F, Majdzadeh R, Pourreza A, Mohammad K, et al. Measuring household exposure to catastrophic health care expenditures: a Longitudinal study in Zone 17 of Tehran. Hakim. 2009;12(2):38-47.

8. Daneshkohan A, Karami M, Najafi F, Matin BK. Household catastrophic health expenditure. Iran J Public Health. 2011;40(1):94-9.

9. Kavosi Z, Keshtkaran A, Hayati R, Ravangard R, Khammarnia M Household financial contribution to the health System in Shiraz, Iran in 2012. Int J Health Policy Manag. 2014;3(5):243-9.

10. Xu K, Evans DB, Kawabata K, Zeramdini R, Klavus J, Murray CJ. Household catastrophic health expenditure: a multicountry analysis. Lancet. 2003;362(9378):111-7.

11. Gotsadze G, Zoidze A, Rukhadze N. Household catastrophic health expenditure: evidence from Georgia and its policy implications. BMC Health Serv Res. 2009;9:69.

12. Hotchkiss DR, Rous JJ, Karmacharya K, Sangraula P. Household health expenditures in Nepal: implications for health care financing reform. Health Policy Plan. 1998;13(4):371-83.

13. do Rosario Giraldes M. [Equity in socioeconomic areas with impact on health in countries of European Union]. Cad Saude Publica. 2001;17(3):533-44.

14. Meskari AM, Amiri Anabad H. The study of economic burden of health care costs for rural and urban households in Iran during 19812001.; 2011.

15. Khosravi M, Kazemian M. The Evaluation of Rural Health Insurance Plan Based on. .

16. Horizontal and Vertical Equities Situation International Journal of Healthcare. Insur Eq. 2013;1(1).

17. Kazemian M. Iran's National Health Accounts: Years 1971-2001, Analytical Framework and Methodological Issues. Malaysia J Pub Health Med. 2005;5(2):149-65.

18. Mohammadalizadeh Hanjani H, Fazaeli AA. Equity status in Iran Health system financing. Soc Welfare J. 2008;5:289-99.

19. Fazaeli AA. Health financial equity indices trend.; 2008.

20. Karami M, Najafi F, Karami Matin B. Catastrophic health expenditures in kermanshah, west of iran: magnitude and distribution. J Res Health Sci. 2009;9(2):36-40. 